\title{
Association of serum osteoprotegerin with severity of chronic liver disease in female patients: A potential biomarker
}

\author{
Saba Tariq ${ }^{1}$, Sundus Tariq², \\ Shaista Hussain ${ }^{3}$, Mukhtiar Baig ${ }^{4}$
}

\begin{abstract}
Objective: To determine the association of serum osteoprotegerin (OPG) with the severity of chronic liver disease in female patients.

Methods: This case-control study was conducted in Madina Teaching Hospital from 2019-2020.An institutional review board of University Medical and Dental College, The University of Faisalabad gave the approval to conduct the study. Only female patients of age group 40 to 60 years having CLD were included in this study. Total 80 participants were enrolled after fulfilling the inclusion and exclusion criteria. Serum OPG levels were measured by enzyme linked immunosorbant assay (ELISA) supplied by ELAB Sciences, USA. The severity of disease was assessed by Child-Pugh classification.

Results: OPG levels were significantly different between the three Child-Pugh classes. OPG levels were significantly high in class C indicating increased level of this cytokine in CLD as compared to class $A$ ( $p=$ $<0.05)$. There was a positive association of OPG with splenomegaly $(O R=2.10, p=<0.001)$, hepatomegaly $(\mathrm{OR}=4.41,(p=<0.05)$, skin pigmentation $(\mathrm{OR}=2.06, p=<0.05)$, malena $(\mathrm{OR}=1.87, p=<0.05)$ and prolonged bleeding $(\mathrm{OR}=1.86, p=<0.05)$.

Conclusion: The levels of serum Osteoprotegerin is increased in severe form of chronic liver disease (Class C) of Child-Pughs classification as compared to mild (Class A) and moderate (Class B) forms of Child-Pughs classification.
\end{abstract}

KEYWORDS: Osteoprotegerin, Chronic liver disease, liver cirrhosis, Hepatomegaly.

doi: https://doi.org/10.12669/pjms.36.6.2678

How to cite this:

Tariq S, Tariq S, Hussain S, Baig M. Association of serum osteoprotegerin with severity of chronic liver disease in female patients: A potential biomarker. Pak J Med Sci. 2020;36(6):1325-1329. doi: https://doi.org/10.12669/pjms.36.6.2678

This is an Open Access article distributed under the terms of the Creative Commons Attribution License (http://creativecommons.org/licenses/by/3.0), which permits unrestricted use, distribution, and reproduction in any medium, provided the original work is properly cited.

1. Saba Tariq, MBBS, M.Phil.

Associate Professor of Pharmacology,

University Medical \& Dental College, University of Faisalabad,

Pakistan, Research Scholar, Pharmacology,

University of Health Sciences, Lahore, Pakistan.

2. Sundus Tariq, MBBS, M.Phil.

Associate Professor of Physiology,

University Medical \& Dental College, Faisalabad, Pakistan.

Research Scholar, Physiology, University of Health Sciences,

Lahore, Pakistan.

3. Shaista Hussain, MBBS.

House Officer, Allied Hospital Faisalabad, Faisalabad, Pakistan.

4. Prof. Mukhtiar Baig, MBBS, M.Phil., PhD.

Department of Clinical Biochemistry, Faculty of Medicine,

Rabigh, King Abdulaziz University, Jeddah- 21589, KSA.

Correspondence:

Saba Tariq, MBBS, M.Phil.

Associate Professor of Pharmacology,

University Medical \& Dental College, University of Faisalabad,

Faisalabad-38000, Pakistan. Research Scholar, Pharmacology,

University of Health Sciences, Lahore, Pakistan.

Email: drsabatariq1@gmail.com

* Received for Publication:

April 14, 2020

* Revision Received:

* Revision Accepted:

July 16, 2020

July 20, 2020

\section{INTRODUCTION}

The extent of public health burden of Chronic liver disease (CLD) is becoming so frequent that it is considered as one of the main cause of death in underdeveloped countries. ${ }^{1}$ The most frequently encountered causes of CLD includes infection with Hepatitis B and C virus, alcoholic liver disease and non-alcoholic fatty liver disease. ${ }^{2}$

The main mechanism for the progression of CLD is the inflammation of supporting network of liver resulting in hepatic scarring and disturbed architecture due to assembling of collagens and proteoglycans that leads to liver cirrhosis. ${ }^{3}$ Cirrhosis is one of the complication of CLD and can be characterized as the formation of small irregular non-neoplastic masses that are encircled by dense bands of fibrosis that leads to raised blood pressure in portal venous system and chronic liver failure. ${ }^{4}$ 
RANK, RANKL and OPG are the members of TNF superfamily and osteoprotegerin competes with RANKL for binding with RANK that result in its activation that are necessary to start several biochemical cascades. ${ }^{5}$ Osteoprotegerin to osteoclastogenesis inhibitory factor proportion is higher in those having CLD. Osteoprotegerin levels are elevated as a compensatory response to halt the bone loss which is common in CLD. ${ }^{6} \mathrm{~A}$ recent research shows, that there is up-regulation of gene expression of these members of TNF superfamily in serum of patients with jaundice that results in elevation of serum osteoprotegerin in patients of chronic liver disease. ${ }^{7}$

Data suggests that there is significant association between serum levels of osteoprotegerin and functions of albumin and prothrombin indicating that there is a correlation between increased levels of elevated osteoprotegerin and disturbed hepatic physiology. ${ }^{8}$ Sustained release of OPG in patients of CLD has been demonstrated that it must be due to the mediators involved in inflammation indicating that these members of TNF superfamily perform a modulatory action in inflammation. ${ }^{9}$ Another study shows that there is a correlation between serum osteoprotegerin levels in patients having hepatitis $C$ virus infection of prolonged duration with many cardiovascular complications. ${ }^{10}$

As chronic liver disease is one of the most prevalent diseases in Pakistan therefore the present study was designed to see relationship of serum OPG with severity of chronic liver disease in female patients.

\section{METHODS}

The present study was conducted in Madina Teaching Hospital, Faisalabad. This case-control study was conducted in the year 2019-2020. An institutional review board of University Medical and Dental College, The University of Faisalabad gave the approval to conduct this study according to Helsinki Declaration of Human Rights vide letter no (TUF/Dean/2019/47). Madina Teaching Hospital is a tertiary care hospital and have access to large number of patients. A written informed consent was taken from all subjects participating in the study. Only female patients of age group 40 to 60 years were included in the study. Sample size was calculated using openEpi calculator. The calculated sample size for cases was 47 and for controls was 14 using confidence level of $95 \%$, power of study $80 \%$, ratio of controls to cases 0.29 , hypothetical proportion of controls with exposure 40, proportion of cases with exposure 79.42, and least extreme odds ratio to be detected $5.79 .{ }^{11}$ Total 80 participants were enrolled in this study; they were categorized into two groups. First group had 50 participants that were having the chronic liver disease due to hepatitis C confirmed through PCR and second group (control) included 30 participants. Patients were included having the evidence of chronic liver disease on evaluation by the consultant physician. Participants with morbid obesity, renal failure, alcoholic liver disease and osteoporosis were excluded from the study as they can interfere with the OPG levels.

From all participants, information was collected on a specially designed proforma. Information was collected related to age and signs and symptoms of CLD. Disease severity was assessed by ChildPugh's classification. Child Pugh's classification is used to determine the severity of liver cirrhosis. There are three major classes of Child Pugh's classification, to categorize the patients into three different classes several different clinical parameters are used and scoring is made on the basis of these parameters. Patients having a score of 5 or 6 are assigned to class A, patients with scores 7-9 are categorized to class B, and patients with scores $10-15$ are categorized to class C. ${ }^{12,13}$

Anthroprometric data was obtained with the help of standard method and general physical examination was performed by trained physician. Blood samples were taken early in the morning (1214 hour fasting) and were centrifuged at $3000 \mathrm{rpm}$ for 10 minutes within the first hour of collection, and the isolated serum samples were stored at $-80^{\circ} \mathrm{C}$ until assayed. OPG levels were measured by enzyme linked immunosorbant assay (ELISA) supplied by ELAB Sciences, USA.

The data was entered and analyzed using SPSS 20. Mean (SD) was given for quantitative continuous variable. Normality of the data was checked by shapiro-wilk statistic. Comparisons between cases and controls was seen using independent sample t-test. Analysis of variance (ANOVA) was used to see the association of disease severity (Child-Pugh classification) with serum OPG levels. Tukey's post-hoc analysis was used to see individual differences between the groups. Comparison of OPG levels with various factors associated with CLD was also seen by independent sample t-test. Association between OPG levels and various signs and symptoms of CLD was checked by binary logistic regression analysis, where signs and symptoms were taken as dichotomous variable. Results of logistic regression were presented as OR. $P<0.05$ was considered statistically significant. 


\section{RESULTS}

The general, anthropometric measures and OPG levels of controls and cases are given in Table-I. The mean (SD) age of controls and cases in this study were 54.14 (8.145) and 53.30 (8.746) respectively. The mean (SD) levels of serum OPG in controls 3.99 (1.427) and cases 3.79 (1.563) were not significantly different $(p=0.615)$. The severity of disease was assessed by Child-Pugh classification. OPG levels were significantly different between the three Child-Pugh classes $(p=0.029)$. Tukey's post hoc analysis showed that OPG levels were significantly high $(\mathrm{p}=0.028)$ in class $\mathrm{C}, 4.356(2.065)$ putting it under the umbrella of severe CLD as compared to class A, 2.832 (0.722) as shown in Table-II. In cases, OPG levels were not significantly different between having positive family history/ no positive family history group $(\mathrm{p}=0.979)$ considering it as an independent variable of family history, ascites/ non-ascites group $(p=0.271)$, use of diuretics/ no use of diuretics group $(p=0.144)$, sodium restricted diet/no sodium restricted diet group $(p=0.958)$, smoker/ non-smoker group $(\mathrm{p}=0.844)$, IV drug abuser/ non- abuser group ( $\mathrm{p}=0.841)$, diabetic/ non-diabetic group $(p=0.961)$, heart failure/ nonheart failure group $(p=0.726)$, renal disease/ non

Table-I: General, anthropometric characters and OPG levels in cases and controls.

\begin{tabular}{|c|c|c|c|}
\hline & $\begin{array}{c}\text { Control (Normal) } \\
n=30 \\
\text { Mean (SD) }\end{array}$ & $\begin{array}{c}\text { Cases (CLD) } \\
n=50 \\
\text { Mean (SD) }\end{array}$ & $P$ value \\
\hline Age & $54.14(8.145)$ & $53.30(8.746)$ & 0.675 \\
\hline Height (m) & $1.56(0.063)$ & $1.58(0.074)$ & 0.082 \\
\hline Weight (kg) & $66.93(10.222)$ & 75.62 (17.083) & $0.015^{*}$ \\
\hline BMI & $27.69(4.900)$ & $30.16(6.768)$ & 0.090 \\
\hline $\begin{array}{l}\text { Waist } \\
\text { circumference }(\mathrm{c}\end{array}$ & $78.28(6.430)$ & $84.22(12.616)$ & $0.021^{*}$ \\
\hline $\begin{array}{l}\text { Hip } \\
\text { circumference }(c)\end{array}$ & $86.03(5.241)$ & 94.88 (13.573) & $0.001^{*}$ \\
\hline $\mathrm{W} / \mathrm{H}$ ratio & $0.92(0.060)$ & $0.89(0.069)$ & $0.033^{*}$ \\
\hline $\begin{array}{l}\text { Ascites free } \\
\text { weight }(\mathrm{kg})\end{array}$ & $66.93(10.222)$ & $69.20(24.571)$ & 0.637 \\
\hline Pulse & 85.72 (7.959) & 80.92 (6.919) & $0.006^{*}$ \\
\hline $\begin{array}{l}\text { Systolic BP } \\
\text { (mm Hg) }\end{array}$ & 121.38 (14.072) & $126.40(14.813)$ & 0.143 \\
\hline $\begin{array}{l}\text { Diastolic BP } \\
(\mathrm{mm} \mathrm{Hg})\end{array}$ & 80.34 (10.171) & $82.80(10.698)$ & 0.320 \\
\hline Temperature & $98.10(0.310)$ & $98.29(0.701)$ & 0.175 \\
\hline Respiratory rate & $16.76(2.415)$ & $15.36(2.405)$ & $0.015^{*}$ \\
\hline OPG levels & 3.99 (1.427) & $3.79(1.563)$ & 0.615 \\
\hline
\end{tabular}

${ }^{*} \mathrm{p}<0.05$ is considered statistically significant.
Table-II: Severity of disease association with OPG using ANOVA.

\begin{tabular}{lccc}
\hline Child-Pugh classification & \multicolumn{2}{c}{ OPG Levels } & P value \\
\cline { 2 - 3 } & Mean & SD & \\
\hline Class A $(\mathrm{n}=13)$ & 2.832 & 0.722 & $0.029^{*}$ \\
Class B $(\mathrm{n}=19)$ & 4.017 & 1.139 & \\
Class C $(\mathrm{n}=18)$ & 4.356 & 2.065 \\
\hline \multicolumn{4}{c}{ Post hoc analysis Tukey HSD } \\
\hline Groups & Mean difference & SEM & P value \\
\hline Class A vs Class B & -1.184 & 0.567 & 0.105 \\
Class A vs Class C & -1.523 & 0.567 & $0.028^{*}$ \\
Class B vs Class C & -0.339 & 0.534 & 0.802 \\
\hline
\end{tabular}

${ }^{*} p<0.05$ is considered statistically significant.

renal disease group $(p=0.077)$, cancer/ non-cancer group $(\mathrm{p}=0.417)$ and cases doing daily walk/ no walk group $(\mathrm{p}=0.857)$ (Table-III). The binary logistic regression analysis showed that in CLD cases, there was a positive association of OPG with splenomegaly $(\mathrm{OR}=2.10, \mathrm{p}=0.009)$, hepatomegaly $(\mathrm{OR}=4.41, \mathrm{p}=0.012)$, skin pigmentation $(\mathrm{OR}=$

Table-III: Comparison of OPG levels with factors associated with CLD.

\begin{tabular}{|c|c|c|c|c|}
\hline \multirow[t]{2}{*}{ Variables } & & \multicolumn{2}{|c|}{ OPG levels } & \multirow[t]{2}{*}{$p$-value } \\
\hline & & Mean & $S D$ & \\
\hline \multirow{2}{*}{$\begin{array}{l}\text { Positive family } \\
\text { history }\end{array}$} & Yes $(n=16)$ & 3.54 & 1.92 & \multirow[t]{2}{*}{0.979} \\
\hline & No $(n=34)$ & 3.53 & 1.38 & \\
\hline \multirow[t]{2}{*}{ Ascites } & Yes $(n=40)$ & 3.65 & 1.66 & \multirow[t]{2}{*}{0.271} \\
\hline & No $(n=10)$ & 3.04 & 0.98 & \\
\hline \multirow[t]{2}{*}{ Use of Diuretics } & Yes $(n=24)$ & 3.87 & 2.02 & \multirow[t]{2}{*}{0.144} \\
\hline & No $(n=26)$ & 3.22 & 0.87 & \\
\hline \multirow{2}{*}{$\begin{array}{l}\text { Sodium } \\
\text { restricted diet }\end{array}$} & Yes $(n=44)$ & 3.53 & 1.62 & \multirow[t]{2}{*}{0.958} \\
\hline & No $(n=6)$ & 3.56 & 1.02 & \\
\hline \multirow[t]{2}{*}{ Smoking } & Yes $(n=14)$ & 3.46 & 1.24 & \multirow[t]{2}{*}{0.844} \\
\hline & No $(n=36$ & 3.56 & 1.67 & \\
\hline \multirow[t]{2}{*}{ IV drug abuse } & Yes $(n=2)$ & 3.75 & 2.10 & \multirow[t]{2}{*}{0.841} \\
\hline & No $(n=48)$ & 3.52 & 1.56 & \\
\hline \multirow{2}{*}{$\begin{array}{l}\text { Accidental } \\
\text { skin prick }\end{array}$} & Yes $(n=13)$ & 4.01 & 1.57 & \multirow[t]{2}{*}{0.206} \\
\hline & No $(n=37)$ & 3.37 & 1.54 & \\
\hline \multirow{2}{*}{$\begin{array}{l}\text { Diabetes } \\
\text { Mellitus }\end{array}$} & Yes $(n=24)$ & 3.52 & 1.69 & \multirow[t]{2}{*}{0.961} \\
\hline & No $(n=26)$ & 3.54 & 1.45 & \\
\hline \multirow[t]{2}{*}{ Heart failure } & Yes $(n=3)$ & 3.22 & 1.82 & \multirow[t]{2}{*}{0.726} \\
\hline & No $(n=47)$ & 3.55 & 1.56 & \\
\hline \multirow[t]{2}{*}{ Renal disease } & Yes $(n=4)$ & 4.85 & 3.02 & \multirow[t]{2}{*}{0.077} \\
\hline & No $(n=46)$ & 3.42 & 1.36 & \\
\hline \multirow[t]{2}{*}{ Cancer } & Yes $(n=3)$ & 2.82 & 0.33 & \multirow[t]{2}{*}{0.417} \\
\hline & No $(n=47)$ & 3.58 & 1.59 & \\
\hline \multirow[t]{2}{*}{ Daily walk } & Yes $(n=10)$ & 3.61 & 2.21 & \multirow[t]{2}{*}{0.857} \\
\hline & No $(n=40)$ & 3.51 & 1.38 & \\
\hline
\end{tabular}

${ }^{*} p<0.05$ is considered statistically significant. 
Table-IV: Association of OPG with signs and symptoms of CLD.

\begin{tabular}{lcccc}
\hline $\begin{array}{l}\text { Signs and symptoms } \\
\text { of CLD (no/yes) }\end{array}$ & $B^{a}$ & $\begin{array}{c}\text { Exp } \\
(B)^{b}\end{array}$ & p-value & $95 \%$ CI \\
\hline Splenomegaly & 0.74 & 2.10 & $0.009^{*}$ & $1.20-3.69$ \\
Hepatomegaly & 1.48 & 4.41 & $0.012^{*}$ & $1.37-14.13$ \\
Clubbing & -0.42 & 0.66 & 0.377 & $0.26-1.66$ \\
Pigmentation & 0.72 & 2.06 & $0.028^{*}$ & $1.08-3.94$ \\
Menstrual & 0.57 & 1.78 & 0.054 & $0.99-3.19$ \\
$\quad$ disturbance/ Amenorrhea & & & \\
Hemoptysis & -1.66 & 0.19 & 0.365 & $0.005-6.91$ \\
Hematemesis & 0.34 & 1.40 & 0.121 & $0.91-2.17$ \\
Malena & 0.63 & 1.87 & $0.018^{*}$ & $1.11-3.15$ \\
Epistaxis & 0.31 & 1.36 & 0.218 & $0.83-2.22$ \\
Purpura & 0.25 & 1.29 & 0.254 & $0.83-2.00$ \\
Petechiae & 0.31 & 1.35 & 0.178 & $0.87-2.16$ \\
Bruisability & 0.13 & 1.14 & 0.524 & $0.75-1.73$ \\
Prolong bleeding & 0.62 & 1.86 & $0.023^{*}$ & $1.09-3.16$ \\
\hline
\end{tabular}

${ }^{*} \mathrm{p}<0.05$ is considered statistically significant.

${ }^{\mathrm{a}} \mathbf{B}$ - This is the coefficient for the constant (also called the "intercept") in the null mode.

${ }^{b} \operatorname{Exp}(B)$ - This is the exponentiation of the B coefficient, which is an odds ratio.

2.06, $\mathrm{p}=0.028)$, malena $(\mathrm{OR}=1.87, \mathrm{p}=0.018)$, and prolong bleeding $(\mathrm{OR}=1.86, \mathrm{p}=0.023)$. Table-IV.

\section{DISCUSSION}

Cirrhosis is one of the last manifestation of chronic liver disease and is the leading cause of death in such patients. We investigated the serum levels of osteoprotegerin and its association with chronic liver disease especially in relevance to female patients. In the present study, we found a stepwise increase in serum OPG in patients with liver cirrhosis due to hepatitis $B$ and hepatitis $C$, according to $\mathrm{P}$-Ch scores $(\mathrm{A}, \mathrm{B}, \mathrm{C})$. The increase was significant amongst class $A$ versus $C$ of Child-Pugh's classification. We could not found significant difference between mean OPG levels in healthy control and cases. In line with our results, one study found an increase level of OPG in Child-Pugh classification C as compare to A. In their study, they took 30 cirrohotic patients and serological markers were positive for hepatitis $\mathrm{B}$ and C. OPG levels in Child-Pugh A patients was $5.1 \mathrm{pmol} / \mathrm{l}$; range 4.8-5.2 which were significantly lower than those of patients in Group C 6.5 pmol/1; range 4.8-8.4).$^{14}$ The reason for this increase in OPG levels in cirrhotic liver was linked to TGF $\beta$.

In a recently conducted research on mice, they induced cirrhosis in the mice liver with $\mathrm{CCl}_{4}$. The precision cut liver slices of the mice confirmed that on stimulation with TGF $\beta$ liver tissue produces
OPG. Furthermore, they also stimulated 3T3 fibroblast, which secretes TGF $\beta$ that was the main source of stimulation for OPG. Scientist documented that liver injury due to $\mathrm{CCl}_{4}$ causes activation of inflammatory cytokines such as TGF $\beta$, which causes increase secretion of OPG. Further, strengthening their experiment, they remove the toxic stimuli of CCl4 and treatment with interferon alpha not only reversed the fibrosis but also decreased the expression of OPG levels. ${ }^{15}$ In contrast to our study, another study could not found any significant association between Child-Pugh classification and OPG levels. However, they do find significantly increase levels of OPG in cirrohotic patients as compare to control. ${ }^{16} \mathrm{We}$ also compare levels of OPG with sign and symptoms of chronic liver disease, and found a significant positive association of OPG with splenomegaly, hepatomegaly, skin pigmentation, malena, and prolong bleeding. The reason could be as these sign, symptoms appear at later stages of the disease, and OPG levels were high as the severity of the disease rises according to Child-Pugh's classification. Although scarce data is available linking OPG with hepatomegaly. In another study we found an increase levels of OPG in non-alcoholic fatty liver disease in which liver is usually enlarged. ${ }^{17}$ Similarly in another study OPG levels were positively associated with fat content of the liver and researchers were of the view that OPG might play a significant role in development of various liver diseases. ${ }^{18}$

In contrast another study shows a negative relationship of OPG with NAFLD. ${ }^{19}$ The reason for this difference could be that single serum biomarker can only show one aspect of disease progression and there are several modifiable and non-modifiable factors that are responsible for the overall situation. In our study there was not a significant difference of serum Osteoprotegerin levels between cases and controls. As this study includes only female participants and Estrogen can increase Osteoprotegerin levels in control females as supported by another study that estrogen may stimulate OPG expression in various cells at the transcriptional level. The role of microRNA (miRNA) in estrogenmediated OPG production in human osteoblastlike MG63 cells was investigated in this study. The results from ELISA, western blotting and reverse transcription-quantitative polymerase chain reaction (RTqPCR) confirmed that estrogen may upregulate OPG expression. ${ }^{20}$ Estrogen inhibits bone resorption by inducing changes in multiple estrogen-dependent regulatory factors including 
TNF-a and the OPG/RANKL/RANK system. ${ }^{21}$ In another study Serum levels of osteoprotegerin were seen to have a significant positive association with bone mineral density at the lumbar spine, at the femoral neck, total hip in women using estrogen as compared to non-users of estrogen. ${ }^{22}$

Limitation of the study: It includes single center study and small sample size was another limitation of our study.

\section{CONCLUSION}

The levels of OPG, an inflammatory cytokine is increased in chronic liver disease Child-Pughs $\mathrm{C}$ classification and it can be of potential use as a biomarker to diagnose the severity of the disease in such patients.

\section{Grant Support \& Financial Disclosures: None.}

\section{Conflicts of interest: None.}

\section{REFERENCES}

1. Marcellin P, Kutala BK. Liver diseases: A major, neglected global public health problem requiring urgent actions and largescale screening. Liver Int. 2018;38:2-6. doi: 10.1111/liv.13682

2. Gawande A, Gupta GK, Gupta A, Wanjari SJ, Goel V, Rathore V, et al. Acute-on-Chronic Liver Failure: Etiology of Chronic and Acute Precipitating Factors and Their Effect on Mortality. J Clin Exp Hepatol. 2019;9(6):699-703. doi: 10.1016/j.jceh.2019.04.050

3. Andrewartha N, Yeoh G. Human Amnion Epithelial Cell Therapy for Chronic Liver Disease. Stem Cells Int. 2019;2019:8106482. doi: 10.1155/2019/8106482

4. Elaghori A, Salem PE, Azzam E, Elfotoh NA. Ghrelin level in patients with liver cirrhosis. Acta Endocrinologica (Bucharest) 2019;15(1):62. doi: 10.4183/aeb.2019.62

5. Peters S, Clézardin P, Márquez-Rodas I, Niepel D, Gedye C. The RANK-RANKL axis: an opportunity for drug repurposing in cancer? Clin Transl Oncol. 2019:1-5. doi: 10.1007/s12094018-02023-5

6. Lopez-Larramona G, Lucendo AJ, Gonzalez-Castillo S, Tenias JM. Hepatic osteodystrophy: An important matter for consideration in chronic liver disease. World J Hepatol. 2011;3(12):300-309. doi: 10.4254/wjh.v3.i12.300

7. Guanabens N, Pares A. Osteoporosis in chronic liver disease. Liver Int. 2018;38(5):776-785.

8. Garcia-Valdecasas-Campelo E, Gonzalez-Reimers E, SantolariaFernandez F, De La Vega-Prieto MJ, Milena-Abril A, SÁNchezPÉRez MJ, et al. Serum osteoprotegerin and RANKL levels in chronic alcoholic liver disease. Alcohol Alcohol. 2006;41(3):261266. doi: 10.4254 /wjh.v7.i9.1258

9. Rochette L, Meloux A, Rigal E, Zeller M, Malka G, Cottin Y, et al. The role of osteoprotegerin in vascular calcification and bone metabolism: the basis for developing new therapeutics. Calcif Tissue Int. 2019;105(3):239-251. doi: 10.1007/s00223-019-00573-6

10. Pacifico L, Andreoli GM, D'Avanzo M, De Mitri D, Pierimarch $\mathrm{P}$. Role of osteoprotegerin/receptor activator of nuclear factor kappa B/receptor activator of nuclear factor kappa B ligand axis in nonalcoholic fatty liver disease. World J Gastroenterol. 2018;24(19):2073. doi: 10.3748/wjg.v24.i19.2073

11. Moschen AR, Kaser A, Stadlmann S, Millonig G, Kaser S, Mühllechner $\mathrm{P}$, et al. The RANKL/OPG system and bone mineral density in patients with chronic liver disease. J Hepatol. 2005;43(6):973-983. doi: 10.1016/j.jhep.2005.05.034
12. Thüring J, Rippel $\mathrm{O}$, Haarburger $\mathrm{C}$, Merhof $\mathrm{D}$, Schad $\mathrm{P}$, Bruners P, et al. Multiphase CT-based prediction of Child-Pugh classification: a machine learning approach. Eur Radiol Exp. 2020:4:1-9. doi: 10.1186/s41747-020-00148-3

13. Zhao S, Wang M, Yang Z, Tan K, Zheng D, Du X, et al. Comparison between Child-Pugh score and Albumin-Bilirubin grade in the prognosis of patients with HCC after liver resection using time-dependent ROC. Ann Transl Med. 2020;8(8):539. doi: $10.21037 / \mathrm{atm} .2020 .02 .85$

14. Fábrega E, Orive A, Garcia-Suarez C, Garcia-Unzueta M, Antonio Amado J, Pons-Romero F. Osteoprotegerin and RANKL in alcoholic liver cirrhosis. Liver Int. 2005;25(2):305-310. doi: 10.1111/j.1478-3231.2005.01073.x

15. Adhyatmika A, Beljaars L, Putri KS, Habibie H, Boorsma CE, Reker-Smit C, et al. Osteoprotegerin is more than a possible serum marker in liver fibrosis: A study into its function in human and murine liver. Pharmaceutics. 2020;12(5):471. doi: 10.3390/ pharmaceutics12050471

16. Prystupa A, Dąbrowska A, Sak JJ, Tarach J, TorunJurkowska A, LachowskaKotowska P, et al. Concentrations of fetuin-A, osteoprotegerin and a-Klotho in patients with alcoholic liver cirrhosis. Exper Therap Med. 2016;12(5):3464-3470. doi: 10.3892/ etm.2016.3754

17. Ayaz T, Kirbas A, Durakoglugil T, Durakoglugil ME, Sahin SB, Sahin OZ, et al. The relation between carotid intima media thickness and serum osteoprotegerin levels in nonalcoholic fatty liver disease. Metabol Syndr Relat Disord. 2014;12(5):283-289. doi: 10.1089/met.2013.0151

18. Monseu M, Dubois S, Boursier J, Aube C, Gagnadoux F, Leftheriotis G, et al. Osteoprotegerin levels are associated with liver fat and liver markers in dysmetabolic adults. Diabetes Metabol. 2016;42(5):364-367. doi: 10.1016/j.diabet.2016.02.004

19. Yang M, Xu D, Liu Y, Guo X, Li W, Guo C, et al. Combined serum biomarkers in non-invasive diagnosis of non-alcoholic steatohepatitis. PLoS One. 2015;10(6):e0131664. doi: 10.1371/ journal.pone. 0131664

20. Jia J, Zhou H, Zeng X, Feng S. Estrogen stimulates osteoprotegerin expression via the suppression of miR-145 expression in MG63 cells. Mol Med Rep. 2017;15(4):1539-1546. doi: 10.3892/ mmr.2017.6168

21. Hadji P, Colli E, Regidor PA. Bone health in estrogen-free contraception. Osteoporos Int. 2019;30(12):2391-2400. doi: 10.1007/s00198-019-05103-6

22. Stern A, Laughlin GA, Bergstrom J, Barrett-Connor E. The sex-specific association of serum osteoprotegerin and receptor activator of nuclear factor $\mathrm{KB}$ legend with bone mineral density in older adults: The Rancho Bernardo study. Eur J Endocrinol. 2007;156(5):555-562. doi: 10.1530/EJE-06-0753

\section{Authors' Contribution:}

Saba Tariq: Designed the study, data entry, manuscript writing. She is also responsible for the accuracy or integrity of the work.

Sundus Tariq: Statistical analysis and interpretation of data.

Shaista Hussain: Data Collection and drafted the manuscript.

Mukhtiar Baig: Review and final approval of the manuscript. 